\title{
Gamma-aminobutyric acid-B limbic encephalitis and asystolic cardiac arrest: a case report
}

\author{
Christopher A. Ovens ${ }^{1 *}$, Angelo Jayamanne ${ }^{2}$ and Andrew Duggins ${ }^{2}$
}

\begin{abstract}
Background: Gamma-aminobutyric acid-B receptor autoantibodies are becoming an increasingly recognized contributor to the spectrum of autoimmune limbic encephalitis. They are classically associated with seizures and behavioral disturbance, and may coexist with other autoantibodies. Many are paraneoplastic, most commonly associated with small cell lung cancer. Until now there have been no reports of cardiac dysrhythmias in these patients.

Case presentation: A 65-year-old Caucasian man presented with multiple seizures, dysarthria and behavioral disturbance of unclear etiology, with associated asystolic cardiac arrest. Antibody testing showed anti-Gamma-aminobutyric acid-B receptor and anti-Hu antibodies in serum and Gamma-aminobutyric acid-B receptor autoantibodies in cerebrospinal fluid. The diagnosis of small cell lung cancer was subsequently made after lung biopsy, and the patient showed improvement with chemotherapy and intravenous immunoglobulin.

Conclusions: We present the case of a patient with Gamma-aminobutyric acid-B receptor limbic encephalitis associated with asystolic cardiac arrest, an association not previously described. This case illustrates how difficult it is to make the diagnosis on clinical grounds alone. We therefore propose more routine antibody testing in patients with similar symptomatology who remain undifferentiated after initial workup. We also recommend that in the acute setting, patients with Gamma-aminobutyric acid-B receptor encephalitis should receive cardiac monitoring, as further research is required to clarify its possible link with cardiac dysrhythmias.
\end{abstract}

Keywords: GABA Beceptor, Limbic encephalitis, Autoimmune, Paraneoplastic, Anti-Hu, Asystole, Cardiac arrest, Cardiac dysrhythmias

\section{Background}

The Gamma-aminobutyric acid-B receptor $\left(\mathrm{GABA}_{\mathrm{B}}-\mathrm{R}\right)$ is a metabotropic $\mathrm{G}$ protein-coupled receptor expressed on the surface of neurons within the central nervous system. $\mathrm{GABA}_{\mathrm{B}}-\mathrm{R}$ autoantibodies are becoming an increasingly recognized contributor to the broad scope of autoimmune limbic encephalitis. They are associated with a clinical syndrome of seizures, memory impairment and behavioral changes, often in the context of small cell lung cancer (SCLC). $\mathrm{GABA}_{\mathrm{B}}-\mathrm{R}$ antibodies may also coexist with other autoantibodies in patient serum and cerebrospinal fluid (CSF). We present the case of a patient with paraneoplastic anti-GABA ${ }_{B}-R$ and anti-

\footnotetext{
* Correspondence: Christopher.Ovens@health.nsw.gov.au

${ }^{1}$ Nepean Hospital, Penrith, Australia

Full list of author information is available at the end of the article
}

Hu-positive limbic encephalitis, with atypical symptomatology and an associated asystolic cardiac arrest.

\section{Case presentation}

A 65-year-old, right-handed Caucasian man was initially admitted to another hospital after a motor vehicle accident. Prior to the accident, he was an independent truck driver who lived with his wife. He was an ex-smoker of 50 pack-years, and had a significant family history in first-degree relatives of lung, brain, and cervical cancer. Other medical conditions included hypertension, psoriasis, and diverticular disease requiring bowel resection.

The patient was driving a truck alone when he crashed. When paramedics attended, the patient was found in the passenger seat, conscious but confused and combative. At this time, pulse and blood pressure were unmeasurable. Primary and secondary surveys in hospital showed no 
evidence of chest trauma, and the patient suffered only minor soft tissue injuries. In hospital telemetry revealed paroxysmal atrial fibrillation with rapid ventricular response, which was without symptoms and managed only with metoprolol - to the best of our knowledge, no other antiarrhythmic agents were used. Occasional 5-second sinus pauses were also noted, with preceding seizure activity and post-ictal altered level of consciousness for several minutes. Between events, electrocardiography (ECG) was otherwise unremarkable, with no evidence of ischemic changes or other conduction abnormalities. On the fourth day of admission, he became bradycardic and progressed to asystolic arrest requiring 4 minutes of cardiopulmonary resuscitation (CPR). Spontaneous circulation returned in the form of rapid atrial fibrillation. The patient was intubated, and had a temporary pacing wire inserted until a permanent pacemaker was inserted the next day. Cardiac workup, including troponin and electrolyte levels were within normal range. Echocardiography showed a mildly dilated left atrium of $25 \mathrm{~cm}^{2}$, with no other valvular, structural or wall motion abnormalities noted. There was no evidence of right heart strain on echocardiogram or ECG suggestive of pulmonary embolus. A diagnosis of sick sinus syndrome was made, and he was commenced on metoprolol and apixaban. His behavior remained impulsive after extubation, demanding to leave the hospital, and he was discharged several days later. All other investigations at this time, including chest X-ray, electroencephalogram (EEG) and a computed tomography (CT) brain scan, were unremarkable.

One week after discharge, he presented to our hospital with his first observed generalized tonic-clonic seizure (GTCS) lasting 3 minutes, with urinary incontinence and prolonged post-ictal confusion. Repeat EEG and CT brain were reported as normal. This episode was thought to be secondary to hypoxic brain injury after asystolic arrest. $\mathrm{He}$ was discharged on levetiracetam $1 \mathrm{~g}$ twice daily. Two weeks later he presented with another GTCS, and was discharged once stable from Emergency. His third seizure occurred 6 days later, at which time he was admitted and commenced on sodium valproate $500 \mathrm{mg}$ twice daily in addition to levetiracetam. His EEG and CT brain scan were again normal. Two weeks later, his fourth GTCS prompted addition of carbamazepine $200 \mathrm{mg}$ controlled release twice daily. An outpatient magnetic resonance imaging (MRI) brain scan showed no abnormality at this time.

He had three further seizures in 3 weeks, and tolerated several antiepileptic drugs poorly. He was admitted to our hospital 10 weeks after his first seizure due to confusion. Retrospectively, there was significant deterioration in his confusion, agitation, and impulsivity since his initial presentation, in addition to more frequent seizures. Of note, his wife also reported progressive slurring of his speech, difficulty walking, and ongoing back pain over the preceding weeks. Medications at this point were lacosamide $100 \mathrm{mg}$ twice daily, and sodium valproate $1 \mathrm{~g}$ twice daily. He suffered no further seizures, but became agitated and aggressive, requiring one-to-one nursing, regular olanzapine, and four-point limb restraints.

His refractory and progressive symptoms prompted further investigation. EEG was again normal. Lumbar puncture showed normal opening pressures, with CSF findings as follows: leukocytes $2 \times 10^{6} / \mathrm{L}$, mononuclear cells $2 \times$ $10^{6} / \mathrm{L}$, protein $0.61 \mathrm{mg} / \mathrm{dL}$, glucose $3.2 \mathrm{mmol} / \mathrm{L}$. ANNA-1 $(\mathrm{Hu})$ antibodies, $\mathrm{GABA}_{\mathrm{B}}-\mathrm{R}$ antibodies and unmatched oligoclonal bands were also present. Serum was also positive for $\mathrm{GABA}_{\mathrm{B}}-\mathrm{R}$ antibodies but not for anti-Hu antibodies. A chest $\mathrm{CT}$ scan revealed a spiculated mass in the right lung and perihilar lymphadenopathy. A biopsy was obtained via endobronchial ultrasound, which revealed small cell neuroendocrine tumor. A subsequent MRI spine scan revealed diffuse vertebral metastases.

He was commenced on etoposide and carboplatin, as well as a trial of intravenous immunoglobulin (IVIg). Although suffering chemotherapy-related side effects including febrile neutropenia from staphylococcal septicemia, he showed some improvement with this therapy. He remained seizure free, was able to hold a conversation and mobilise independently. His modified Rankin scale (mRS) was 4 prior to treatment, and improved to a mRS of 2 with IVIg and chemotherapy. At 12 weeks follow-up, our patient had only mild short-term memory deficits, but was otherwise at his premorbid level of function.

\section{Discussion}

We report a case of a patient with anti-GABA $A_{B}-\mathrm{R}$ and anti-Hu limbic encephalitis, presenting with progressive seizures and behavioral disturbance, as well as cardiac dysrhythmias. While much of his phenotype was classic of $\mathrm{GABA}_{\mathrm{B}}-\mathrm{R}$ encephalitis, phenotypic overlap is rare and an association with cardiac dysrhythmias has not previously been described. The first paraneoplastic antibodies were to intracellular targets (e.g., anti-Hu, -Ma2, -CRMP5, -amphiphysin). Anti-GABA $A_{B}-\mathrm{R}$ antibodies join the family of the more recently discovered antibodies against cell surface targets, such as anti-NMDAR, -AMPAR, -GlyR, -Caspr2, and -LGI1 [1]. All of the $\mathrm{GABA}_{\mathrm{B}}-\mathrm{R}$-positive patients described by Lancaster et al. [2] presented with early or prominent seizures, with the majority showing limbic dysfunction in the form of confusion, memory disturbance, and behavioral changes. This is thought to be due to the inhibitory action of $\mathrm{GABA}_{B}-\mathrm{R}$ with high density in the hippocampus $[3,4]$. Further case series and case reports have broadened the scope of anti-GABA ${ }_{B}-\mathrm{R}$ syndromes [1-7]. Half were associated with SCLC, (27/53), two were associated with other cancer (thymus carcinoid, melanoma), while the remainder were not paraneoplastic. The majority were associated with 
seizures (46/53), however atypical phenotypes have been reported including cerebellar ataxia, opsoclonus myoclonus, brainstem encephalitis, and status epilepticus. Cerebellar ataxia and opsoclonus myoclonus may be related to high $\mathrm{GABA}_{\mathrm{B}}-\mathrm{R}$ density in the cerebellum $[3,4]$. MRI changes involve high signal in limbic regions on T2/FLAIR images, however MRI was normal in 32\% of patients. Outcomes varied, but the majority showed some improvement with immunotherapies and oncological treatment where tumor was present. Patients with SCLC have poorer survival compared to those without tumor [3].

The presence of dual autoantibodies in our patient (anti-GABA $A_{B}-\mathrm{R}$ and anti-Hu) is notable. Only three patients have previously been described with this combination $[4,5]$. Classically, anti-Hu antibodies confer a poor prognosis and are associated with sensory or sensorimotor neuropathy, however they are not always pathogenic $[4,8]$. Our patient also displays phenotypic overlap. The presence of dysarthria (prominent in our patient) in $\mathrm{GABA}_{\mathrm{B}}-\mathrm{R}$ encephalitis has been described only in the setting of cerebellar ataxia phenotype $[3,5]$ or brainstem phenotype [7]. To the best of our knowledge, dysarthria has not been described in combination with the prominent seizures and behavioral changes of classic limbic encephalitis. This overlap may be due to either anatomically extensive $G_{A B A}-R$ encephalitis (possibly with limbic and cerebellar involvement) or 'silent' anti-Hu antibodies, or due to anti-Hu antibodies modifying a more classical $G_{A B A}-R$ phenotype.

Two controls in a previous study [2] had low titer $\mathrm{GABA}_{\mathrm{B}}-\mathrm{R}$ antibodies and high titer GAD-65 antibodies, and phenotypically resembled a GAD-65 encephalopathy with progressive cerebellar ataxia, rigidity, myoclonus, and gait instability. Similarly, Hoftberger et al. [3] reported a patient with $\mathrm{GABA}_{\mathrm{B}}-\mathrm{R}$ and amphiphysin autoantibodies with a mixed phenotype of limbic encephalitis, diffuse encephalomyelitis and gait ataxia. The significance of antibody titers is still under investigation. Although Lancaster et al. [2] showed no correlation between titer and disease severity, Mundiyanapurath et al. [7] showed a steady decline in titer mapping treatment response. The clinical manifestation of $\mathrm{GABA}_{\mathrm{A}}-\mathrm{R}$ autoimmune encephalitis is dependent on titer. High titers cause encephalitis while low titers invoke seizures, stiff-person syndrome and opsoclonus myoclonus [9]. Thus, while different individuals may have different disease thresholds, titer may help to determine symptomatology when multiple competing antibodies are present.

Our patient's motor vehicle accident was initially thought to be a primary cardiac event, with subsequent asystole and pauses consistent with sick sinus syndrome. If this was the case, then two distinct cardiac events (in addition to other arrhythmias) preceded the development of seizure activity. It is known that elevated levels of S100B, a dimeric calcium-binding protein in brain astrocytes, has been associated with conditions of hypoxia, such as high altitude and obstructive sleep apnoea $[10,11]$. S100B is also believed to be a marker of blood brain barrier (BBB) dysfunction [11]. In addition to hypoxia, acute stress, and epinephrine have also been shown to alter BBB permeability [10]. If the hypoxia or acute stress from cardiac arrest preceded neurological symptoms, it is conceivable that this BBB disruption may have granted serum $\mathrm{GABA}_{B}-\mathrm{R}$ autoantibodies access to cerebral tissue. This would also allow translocation of activated memory $B$ cells into the central nervous system [10], mediating subsequent intrathecal production of autoantibodies similar to the mechanism proposed in multiple sclerosis [12]. However, the fact that our patient's first documented seizure occurred 1 week after his accident casts doubt over this hypothesis, requiring a very rapid humoral response within the central nervous system. It also fails to identify a cause for his sinus dysfunction. Our patient had no history or family history of cardiac disease or sudden death. He had suffered no previous episodes of palpitations, chest pain, or syncope. Aside from a mildly dilated left atrium, there were no other cardiac abnormalities detected on routine workup, and no underlying precipitant for his sick-sinus syndrome was found.

In retrospect, we believe our patient's initial motor vehicle accident to instead be secondary to a seizure. That he was found in the passenger seat raises the possibility of convulsions, and if the force of impact alone were enough to throw him into the passenger seat, we would expect further injuries to be seen on his secondary survey. His agitation and confusion at the scene are consistent with a post-ictal phase. An ictal or post-ictal asystolic event would explain the non-palpable pulses and unrecordable blood pressure at the time of his motor vehicle accident, as well as the sinus pauses on telemetry associated with seizure activity. Ictal and postictal conduction abnormalities are rare but welldescribed complications of seizures, with asystole, bradycardia, and other arrhythmias potentially involved in the pathogenesis of sudden unexplained death in epilepsy patients (SUDEP) [13-15]. In asystole, it is thought that seizure activity disrupts temporal and insular connections with the brainstem and hypothalamus, causing a transient excess of vagal tone [13, 14]. Ictal asystole is classically brief ( $90 \%$ lasting less than 30 seconds) and is always associated with a focal seizure, with or without secondary generalization. Progression to GTCS is associated with prolonged ictal asystole (up to 96 seconds has been reported) [14]. In post-ictal asystole from generalized seizures, the greatest reported delay between seizure and onset of asystole was 158 seconds, asystole duration was 7-60 seconds, and more than half died from probable SUDEP [15]. However, the patient's in-hospital asystolic cardiac arrest would be atypical for ictal asystole, 
lasting more than twice as long as those previously described and lacking preceding seizure activity.

Thus, while it is possible that isolated cardiac dysrhythmias precipitated neurological symptoms, we believe this mechanism to be less likely due to the events surrounding his initial motor vehicle accident, its time course, and the absence of other cardiac abnormalities as a cause. His asystolic arrest is also insufficiently explained purely by a post-ictal mechanism, and as a result we propose a link between our patient's underlying $G_{A B A}-R$ encephalitis and his cardiac dysrhythmias and asystole. Other encephalitides have been associated with asystole and cardiac arrhythmias, including N-methyl-Daspartate receptor (NMDA-R) autoimmune limbic encephalitis [16, 17] and viral encephalitis [18]. In one series of 100 patients more than $1 / 3$ of patients with NMDA-R encephalitis had cardiac dysrhythmias in addition to the classical symptoms of psychiatric and behavioral disturbance $-7 \%$ had prolonged pauses and $4 \%$ required pacemaker insertion [16]. In this series, it is unclear whether these were associated with seizures or not. A smaller series [19] identified $80 \%$ of NMDA-R encephalitis patients with tachycardias, $60 \%$ with sinus bradycardias and $40 \%$ with sinus arrests. The authors suggest that NMDA-R dysfunction within the nodose vagal nuclei and the nucleus of solitary tract (NTS) lead to abnormal vagal responses capable of tachyarrhythmias, bradycardias, and asystole. $\mathrm{GABA}_{\mathrm{B}}$-Rs have been shown to populate similar areas of the brain including the NTS and vagal nuclei [19-21]. They have similarly been implicated in modulating vagal cardiorespiratory reflexes in animal models $[20,22,23]$. It is possible that in our patient, a similar disruption of vagal reflexes by $\mathrm{GABA}_{\mathrm{B}}-\mathrm{R}$ antibodies may account for his sinus node dysfunction, pauses, and asystolic arrest. Interestingly, Nazif noted a progressive bradycardia and subsequent arrest in vagally mediated NMDA-R asystole, and a similar progression was seen in our patient [19]. However, it is unclear whether a significant vagal stimulus was present prior or not. This mechanism of autonomic dysregulation and vagal disturbance has also been proposed to explain ictal asystole, and may represent a common pathway in these patients $[13,14]$. Thus we propose an association between $\mathrm{GABA}_{\mathrm{B}}-\mathrm{R}$ limbic encephalitis and cardiac dysrhythmias, which has not previously been described.

\section{Conclusions}

In summary, we present a 65-year-old man with anti$\mathrm{GABA}_{B}-\mathrm{R}$ and anti-Hu paraneoplastic limbic encephalitis secondary to small cell lung cancer, with associated asystolic cardiac arrest. The cause for this patient's arrhythmias, seizures, and confusion was initially obscure, and remained so even after imaging and routine blood workup.
The initial diagnosis of hypoxic brain injury was called into question by the progressive nature of his symptoms, his dysarthria and ongoing back pain. Given the diverse phenotypes associated with cell surface autoimmune encephalitides, and given that clinical outcome depends on early diagnosis in these conditions (especially when associated with tumor), a case can be made for more routine screening in patients who show progressive and refractory neurological symptoms and who remain undifferentiated after initial workup. In light of this case, telemetry is also warranted in those patients with confirmed $G_{A B A}-R$ encephalitis to further clarify any association with cardiac dysrhythmias.

\section{Abbreviations \\ BBB: Blood brain barrier; CSF: Cerebrospinal fluid; CT: Computed tomography; ECG: Electrocardiography; EEG: Electroencephalogram; $G A B A_{B}-R: G A B A_{B}$ receptor; GTCS: Generalized tonic-clonic seizure; IVlg: Intravenous immunoglobulin; MRI: Magnetic resonance imaging; NMDA-R: N-methyl-D- aspartate receptor; SCLC: Small cell lung cancer; SUDEP: Sudden unexplained death in epilepsy patients}

\section{Acknowledgements \\ Not applicable.}

\section{Funding}

Not applicable.

\section{Availability of data and materials Not applicable.}

\section{Authors' contributions}

CAO performed the literature search and was the major contributor to the manuscript. AJ provided guidance and reviews throughout the writing process, and aided in the literature search. AD reviewed the manuscript and guided the discussion. All authors read and approved the final manuscript.

Ethics approval and consent to participate Not applicable.

\section{Consent for publication}

Written informed consent was obtained from the patient for publication of this case report and any accompanying images. A copy of the written consent is available for review by the Editor-in-Chief of this journal.

Competing interests

The authors declare that they have no competing interests.

\section{Publisher's Note}

Springer Nature remains neutral with regard to jurisdictional claims in published maps and institutional affiliations.

\section{Author details \\ ${ }^{1}$ Nepean Hospital, Penrith, Australia. ${ }^{2}$ Nepean Hospital Neurology Department, Penrith, Australia.}

Received: 6 September 2017 Accepted: 20 November 2017 Published online: 29 December 2017

\section{References}

1. Lancaster E, Martinez-Hernandez E, Dalmau J. Encephalitis and antibodies to synaptic and neuronal cell surface proteins. Neurology. 2011;77:179-89.

2. Lancaster E, Lai M, Peng X, Highes E, Constantinescu R, Raizer J, Friedman D, Skeen MB, Grisold W, Kimura A, Ohta K, lizuka T, Guzman M, Graus F, Moss SJ, Balice-Gordon R, Dalmau J. Antibodies to the GABAb receptor in limbic encephalitis with seizures: case series and characterisation of the antigen. Lancet. 2010;9:67-76. 
3. Hoftberger R, Titulaer MJ, Sabater L, Dome B, Rozsas A, Hegedus B, Hoda MA, Laszlo V, Ankersmit HJ, Harms L, Boyero S, de Felipe A, Saiz A, Dalmau J, Graus F. Encephalitis and GABAb receptor antibodies. Neurology. 2013:81:1500-6.

4. Kim T-J, Lee S-T, Shin J-W, Moon J, Lim J-A, Byun J-I, Shin Y-W, Lee K-J, Jung K-H, Kim Y-S, Park K-I, Chu K, Kee SK. Clinical manifestations and outcomes of the treatment of patients with GABAb encephalitis. J Neuroimmunol. 2014;270:45-50.

5. Boronat A, Sabater L, Saiz A, Dalmau J, Graus F. GABAb receptor antibodies in limbic encephalitis and anti-GAD-associated neurological disorders. Neurology. 2011;76:795-800.

6. Jarius S, Steinmeyer F, Knobel A, Streitberger K, Hotter B, Horn S, Heuer H, Schreiber SJ, Wilhelm T, Trefzer W, Wildemann B, Ruprecht K. GABAB receptor antibodies in paraneoplastic cerebellar ataxia. J Neuroimmunol. 2013:256:94-6.

7. Mundiyanapurath S, Jarius S, Probst C, Stocker W, Wildemann B, Bosel J. GABA-B-receptor antibodies in paraneoplastic brainstem encephalitis. J Neuroimmunol. 2013;259:88-91.

8. Gromadzka G, Karlinska AG, Lysiak Z, Blazejewska-Hyzorek B, Litwin T, Czlonkowska A. Positivity of serum "classical" onconeuronal antibodies in a series of 2063 consecutive patients with suspicion of paraneooplastic neurological syndrome. J Neuroimmunol. 2013;259:75-80.

9. Joubert B, Honnorat J. Autoimmune channelopathies in paraneoplastic neurological syndromes. Biochem Biophys Acta. 2015;1848:2665-76.

10. Moscato EH, Jain A, Peng X, Highes EG, Dalmau J, Balice-Gordon RJ. Mechanisms underlying autoimmune synaptic encephalitis leading to disorders of memory, behaviour and cognition: insights from molecular, cellular and synaptic studies. Eur J Neurosci. 2010;32(2):298-309.

11. Winter CD, Whyte T, Cardinal J, Kenny R, Ballard E. Re-exposure to the hypobaric hypoxic brain injury of high altitude: plasma S100B levels and the possible effect of acclimatisation of blood-brain barrier dysfunction. Neurol Sci. 2016;37:533-9.

12. Hauser SL, Waubant E, Arnold DL, Vollmer T, Antel J, Fox RJ, Bar-Or A, Panzara M, Sarkar N, Agarwal S, Langer-Gould A, Smith CH. B-cell depletion with rituximab in relapsing-remitting multiple sclerosis. N Engl J Med. 2008; 358:676-88.

13. Britton JW, Benarroch E. Seizures and syncope: Anatomic basis and diagnostic considerations. Clin Auton Res. 2006;16:18-28.

14. Tenyi D, Gyimesi C, Kupo P, Horvath R, Bone B, Barsi P, Kovacs N, Simor T, Siegler Z, Kornyei L, Fogarasi A, Janszky J. Ictal Asystole: A systematic review. Epilepsia. 2017;58(3):356-62.

15. van der Lende M, Surges R, Sander JW, Thijs RD. Cardiac arrhythmias during or after epileptic seizures. J Neurol Neurosurg Psychiatry. 2015;87:69-74.

16. Dalmau J, Gleichman AJ, Hughes EG, Rossi JE, Peng X, Lai M, Dessain SK Rosenfeld MR, Balice-Gordon R, Lynch DR. Anti-NMDA-receptor encephalitis: case series and analysis of the effects of antibodies. Lancet Neurol. 2008; 7(12):1091-8.

17. Ziaeian B, Shamsa K. Dazed, Confused and Asystolic: Possible Signs of Anti-N-Methyl-D-Aspartate Receptor Encephalitis. Tex Heart Inst J. 2015; 42(2):175-7.

18. Alsolaiman MM, Alsolaiman F, Bassas S, Amin DK. Viral Encephalitis Associated with reversible Asystole Due to Sinoatrial Arrest. South Med J. 2001;94(5):540-1.

19. Nazif TM, Vazquez J, Honig LS, Dizon JM. Anti-N-methyl-D-aspartate receptor encephalitis: an emerging cause of centrally mediated sinus node dysfunction. Europace. 2012;14:1188-94.

20. Blackshaw LA, Smid SD, O'Donnell TA, Dent J. GABAb receptor-mediated effects on vagal pathways to the lower oesophageal sphincter and heart. $\mathrm{Br}$ J Pharmacol. 2000;130:279-88.

21. Rohof WO, Aronica E, Beaumont H, Troost D, Boeckxstaens GE. Localization of mGluR5, GABAb, GABAa, and cannabinoid receptors on the vago-vagal reflex pathway responsible for transient lower esophageal sphincter relaxation in humans: an immunohistochemical study. Neurogastroenterol Motil. 2012;24:383-92.

22. Silva-Carvalho L, Dawid-Milner MS, Spyer KM. The pattern of excitatory inputs to the nucleus tractus solitarii evoked on stimulation in the hypothalamic defence area in the cat. J Physiol. 1995;487(3):727-37.

23. Wang $Y$, Jordan D, Ramage AG. Autonomic neuroscience: basic and clinical. Auton Neurosci: Basic Clin. 2009;152:75-83.

\section{Submit your next manuscript to BioMed Central and we will help you at every step:}

- We accept pre-submission inquiries

- Our selector tool helps you to find the most relevant journal

- We provide round the clock customer support

- Convenient online submission

- Thorough peer review

- Inclusion in PubMed and all major indexing services

- Maximum visibility for your research

Submit your manuscript at www.biomedcentral.com/submit
Biomed Central 